\title{
Implication of Metaphor in Language Teaching
}

\author{
Yan $\mathrm{Xu}$ \\ Foreign Language School \\ Huanghe Science and Technology College \\ Zhengzhou, China
}

\begin{abstract}
Metaphor is a synthesis combined with form, meaning, pragmatic function and personality emotion, instead of a simple form. The correct understanding of a novel metaphor is partially determined by the expected mastery of cultural knowledge. This paper mainly explores the definition of metaphor, classification, interpretation and implication in language teaching.
\end{abstract}

Keywords-metaphor; definition; interpretation; language teaching

\section{INTRODUCTION}

Metaphor understanding involves both cognitive and socio-cultural factors. As a result, it is implicated that novel metaphor is radically culture-specific. The correct understanding of a novel metaphor is partially determined by the expected mastery of cultural knowledge. Therefore, social and cognitive factors affect our interpretation of any novel expression, especially novel metaphors. It is assumed that, a language is not a monolith but a complex network of variants in constant flux. Expression may serve to carry their users' messages, but they also carry social values (Milroy, 1994). Furthermore, the meaning is negotiated between participants in an interaction (Brumfit, 1994). In brief, the present study of novel metaphor further confirm the argument that language can be viewed both as a social institution and as experienced by a single individual, which is necessarily limited by that individual's personal life history.

\section{LITERATURE REVIEW}

\section{A. Definition of metaphor}

Metaphor comes from the ancient Greece words 'meta' and 'pherein' 'meta' means 'across', 'pherein' means 'change'; Therefore the basic function of metaphor is to transform something from one place to another. From semantic view, there are three basic factors composing a metaphor: the tenor, the vehicle, the ground, not all of which need to be presented in a metaphor, that is, some of them may be hidden. Therefore, it is very important to distinguish three factors from each other when facing a metaphor.

The Random House Unabridged Dictionary (second addition) define metaphor as "a figure of speech in which a term or phrase is applied to something to which it is not literally applicable in order to suggest a resemblance." While according to BB English Dictionary, "metaphor is a way of describing something by saying that it is something else which has the qualities that you are trying to describe."

Metaphor is a figurative phenomenon, an important tool in language communication; what's more, it has a closed relationship with many subjects, such as Literature, Aesthetics, Sociology, Philosophy, Logic and so on, for metaphor can permeate into one's subjective thinking and concept of aesthetic. One's personality, including philosophy, culture, standard of aesthetics and so on, will be reflected through the metaphor one uses. Therefore, metaphor should be studied from a more profound and higher level.

Metaphor is a process by which we conceive "one thing in terms of another, and its primary function is understanding" (Lakoff and Johnson, Metaphors We Live By 36). That is, we often do (and must) talk about things that do not physically exist, that we cannot reach out and touch or take apart with our hands to see what is inside and how it works: love, time, anger, life. Sometimes these intangibles are emotions (love, anger); sometimes they are abstractions or names for a whole range of things or activities (argument, friendship). We make them tangible by, in a process of thought, applying models of physical things to them: love is falling; argument is war. This kind of thinking is carried on by us and our culture almost unconsciously -- you would probably not answer someone who asks, "What are you doing?" with, "Oh, nothing, just thinking about argument as war." Where do we see evidence of these thought processes? When someone says, "I defended my position and he backed off," he or she is "thinking" about argument as war whether conscious of it or not. In our Western culture, arguments are typically seen as combative and competitive, but one could imagine cultures in which argument was conceived of as dance. Such a culture would have a different language than ours -- even if it were English!! In that culture, it would be possible to say, "I twirled his idea, then did a dip" -- not only possible to say it, but you would habitually say it (it wouldn't be poetry or some extraordinary or creative use of language) and everyone would know instantly what you mean. It would be a matter of usage -- the way words are typically used in a language and a culture.

\section{B. The classification of metaphor}

From Peter Newmark's view A Textbook of Translation, 'I have suggested elsewhere that there are four types of metaphor: fossilized, stock, recently created and original'. From the beginning, the fossilized, the name itself is a metaphor. It literally means to become a fossil; actually it 
means the trite, our-of-date, merely used. Take 'rain casts and dogs' as an example. Nowadays those who used this metaphor are regarded as the people who live in the generation before the grandfather. The stock refers to the metaphors that have been taken in the dictionaries for the usage of metaphorical meanings and are still frequently used in daily life. Also, there are the recently created metaphors which have not yet been adopted in the dictionary but can be accepted the common people with a feeling of refreshness. The last one, the original are regarded as the product from the inspired thought of the men full of wits and knowledge, and can hardly be seen before, let along have been recorded in dictionary.

Since the Latin word translatio, like the Greek metaphora, can be used to mean both metaphor and translation, this has suggested a historical identification (Copeland 1991: 235). Yet, as Cheyfitz argues, just because the verb metaphero can refer to both interlingual translation and the transference of sense within a language, that isn't simply what 'brings the idea of metaphor within the context of translation or the idea of translation within the context of metaphor'(1991:36). For it is precisely Aristotle's reference to the transference of an alien name that shows how metaphor grounds itself in a territorial imperative, in a division between the domestic and the foreign. Within Aristotle's theory of metaphor there is a theory that has exerted and continues to exert 'a controlling force on the way Westerners think about language, the figurative becomes the foreign, or strange; the proper becomes the national, or normal.'

Gregory Rabassa argues that 'a word is nothing but a metaphor for an object or...for another word', and that translation is 'a form of adaptation, making the new metaphor fit the original metaphor'(1989:1-2). For Rabassa, translation is the piecing together of metaphors, in order to construct another entity which is also a metaphor: metaphor as a metaphor for translation.

Scholars agree that metaphor has been sadly neglected in translation theory. In the standard works of the linguistically oriented schools(Nida 1964; Nida and Taber 1969; Reiss 1971; Wilss 1977; Koller 1979) the topic is barely discussed, and in Mounin's classic study(1967) it is not even mentioned. The subject was taken up by Menachim Dagut in 1976 in an essay entitled "Can'Metaphor'be translated? ," a further essay "The limits of translation exemplified by metaphor translation" by Raymond van den Broeck appeared in 1981, while Newmark devoted a chapter of his pragmatically and linguistically oriented book Approaches to Translation(1981) to the issue "The translation of metaphor."

\section{Interpretation of metaphor}

From the theoretical perspective the lack of an explicit account of the nature of metaphor has given rise to a number of misconceptions about metaphor. According to Lason(1984), "Metaphors and similes are grammatical forms which represent two propositions in the semantic structure"that are related to each other by way of comparison, where "the comparison is always that of some likeness"'(1984:246)
Firstly, difficulties confronted lie in the different cultural background shared by the source language's writers and the target language's readers. In fact, most obstacles can be traced back to the culture clash. Therefore, metaphors are stamped with the culture of society, which have great impacts on every aspect of people's life. At the same time, Tradition and custom have great influences on the way of people' thinking; therefore, metaphor, as a proportion of language, comes out of people's mind, which has been laid with the brand of the custom and tradition of their country.

In addition, the fact that the same metaphor can be interpreted by readers in quite different ways further confirms the assumption that the practice of translation is a risky undertaking, requiring not simply the exchange of linguistically packaged ideas, but an effort of imagination and analogical reasoning on the part of the context.

What's more, the importance of individual differences in understanding metaphor should not be neglected. The reason is that different readers have different understanding towards the same metaphor. The differences between readers include different educational background, different cultural surroundings and different imagery ability. These differences are supposed to affect the understanding of metaphor, which can not be neutralized. According to relevance theory, it claims that characteristic misunderstanding will occur if, in such circumstances, the reader simply chooses the interpretation which is optimally relevant to him without considering other factors. Thus, it leads to misunderstanding the metaphor. All in all, interpretation of metaphor is not easy because we should take many elements into consideration, especially the cultural background of the western countries. Only in this way can we analyze and understand metaphor exactly.

Newmark suggested that there are five methods of understanding metaphor; transferring the image, finding an equivalent image, converting the metaphor to a simile or sense plus the simile; finally, most frequently, converting the image to sense, which may involve analysis in several components, including figurative and concrete elements. In other words, the first solution is to translate by a metaphor using the same or a similar image (vehicle) ('a ray of hope'; ein Hoffnungsstrahl); the second is to translate with a different image that has the same sense; the third is to convert the metaphor into a simile; the fourth is to quality the simile with the sense (c'est un lion $=$ 'he is as brave as a lion'), which in communicative translation may be advisable, if the metaphor is obscure; the fifth is to translate as much as possible of the sense beind the image, the sense being the common area between the metaphor's object and the image, as seen by the writer and interpreted by the translator. The question of whether to use semantic or communicative translation will arise only when the translator is in doubt about which solution to adopt. Further, the translator has to consider cultural, universal and personal elements in the metaphor, and whether communicative or semantic translation is to be used.

However, on the whole, there are three ways to translate the metaphors. It involves literal translation, free translation 
and Combination of literal and free translation. As far as literal translation, as sharing the living environment----the earth, all human beings would have something in common. Therefore, there would be similarities among the culture of different countries, that is, equivalent expressions would exist among the languages. On condition that the tenor and the vehicle, the construction of metaphor in source language have the same usage in the target language, literal translation is the best way to keep the vivid image and the effect of source metaphor. On the other hand, the culture clash results in the clash of language. Among the tenor and the vehicle and the construction of metaphor of source language, not all could find the same usage in target language; therefore, equivalent images or constructions in target language should be found to replace that of source language, or the metaphorical effect of source language would be decreased. By the way, if the equivalent image or construction could not be found in target language, which is very common, there would be no way but completely free translation. Additionally, As metaphor reflects the customs, living condition, folk tales of its nation, compensations are needed in the translation to help to understand the metaphorical meaning of sources language. Although images of source language may be found in the target language, they have not the metaphorical meanings of source language. In that case, combination of literal and free translation could help to convey the metaphorical meanings.

Van den Broeck conceives the treatment of metaphors as a functional relevancy to the communicative situation (1981). Mary Fung also considers translating metaphor as a communicative event which is both interlingual and intercultural(1995).Different from the semantic, cultural and functional perspectives mentioned above, Newmark holds a more pragmatic approach. Drawing on his practical experience, he proposes several procedures for translating metaphor: (1)Reproducing the same image in the target language; (2)Replacing the SL image with another established TL image; (3) Replacing the metaphor by simile; (4) Retaining the metaphor and adding the sense;(5) Converting the metaphor to sense; (6) Omitting the metaphor if it is redundant.

Discussions of the subject, especially those written in Chinese, are also pragmatic rather than theoretical. In E-C Translation Coursebook (1980) which is the most widely used translation textbook in China, Zhang Peiji and his cocompilers summarized three popular methods for translating metaphors: (1) Literal translation (similar to Newmark's first procedure); (2) Replacing the SL image with a standard TL image (similar to Newmark's second procedure); (3) Converting the metaphor to sense (Same as Newmark's fifth procedure).Based on the methods suggested by Zhang and his colleagues, Guo Zhuzhang proposes five in A Practical Coursebook in Translation Between English and Chinese (1996, revised edition): (1) Literal translation plus explanation; (2) Literal translation plus meaning; (3) Adapting the metaphor;(4) Using Chinese couplets to render the English metaphor; (5) Replacing the SL image with a TL image Whether a metaphor is "translatable", how difficult it is to translate, how it can be translated and whether it should be translated at all cannot be decided by a set of abstract rules, but must depend on the structure and function of the particular metaphor within the text concerned. In other words, specific context plays an important role in the understanding of metaphor. The meanings of metaphor are different in different contexts. How can the translator find out the implicit meaning of metaphor? Larson suggests: "Often the context in which a metaphor is used will give clues which will help in the interpretation"(1984:249). Sperber and Wilson (1986b) not only offer an explicit account of how the implicatures of figurative language are conveyed, but have also shown that the very point of figurative uses of language is that they convey a wider range of propositions, even in the case of highly standardized metaphors. For example,

- This room is a pigsty. (1986a:236) Having pointed out that, perhaps due to some stereotyped assumptions, such standardized metaphors typically convey "one or two dominant and highly accessible assumptions", in this case perhaps "the implication that the room is filthy and untidy"(2986a:236). However, the speaker must have intended to convey something more than this if the relative indirectness of the utterance is to be justified: an image, say, of filthiness and untidiness beyond the norm, beyond what could have been satisfactorily conveyed by saying merely "This room is filthy and untidy". Thus even this highly standardized example cannot be paraphrased without loss. (1986a:236) Therefore, it can be also interpreted that the owner is a lazy man.

- Life is a box of chocolates. Translators are likely to interpret it differently, based on different assumptions. If they entertain the assumption that the chocolates are sweet, then it will imply that life is sweet and pleasant; if they hold the assumption that a box of chocolates is very diversified and different, then it will imply that life is probably unpredictable. Different assumptions lead to different implications, resulting in different interpretations of the utterance. In this case, translators should take the role of context into consideration.

\section{IMPLICATION IN LANGUAGE TEACHING}

To begin with, on the perspective of the cultivation of students' critical thinking skills, the teachers should make full use of metaphors to greatly enhance the rhetorical effects and make the expressions of the sentences vivid and interesting, which will stimulate the students' metaphor awareness. For example, "There are too many facts here for me to digest them all. I just can't swallow that claim". Actually, it's hard for students to understand the meaning of "swallow that claim". What the teachers should introduce the conceptual metaphor -"Ideas are food". After getting to know the conception of metaphor, the students will grasp the usage of metaphor and learn that metaphors are not only rooted in poems, but also widely used in our daily life. Also, teachers should be competent to select and use metaphors that are suitable for students. In the process of English teaching, when students encounter the sentence, such as "Life is a novel", the teachers should ask students think over 
the meaning of the metaphor with the clue that the meaning of life is not its length but its quality that counts. Then, another metaphors will be produced, such as "Life is a journey or Life is a stage" etc. Subsequently, the students are supposed to be divided into several groups and conduct the group activity in which every member of the group should produce metaphor expressions with objects selected by themselves and share the reasons. The study indicates the higher capacity of metaphors interpretation and expressions the teachers have, the easier the students' critical thinking skills can be improved.

Secondly, concerning cultural teaching, it is divided into three stages, including the beginning stage, the intermediate stage and the advanced stage. The teachers are required to reveal the cultural background and meanings of the vocabulary related in the beginning stage, in which the students are led to study the usage of metaphor, especially polyseme in the beginning stage. For example, the word "handicap", is formed by hand in cap. While it originates from the story that people in the ancient time exchanged their articles by articles and the trade will be successful only when the judger put his hand in the cap to decide. Subsequently, "handicap" refers to hardship or obstacle nowadays. The "handicapped", used as metaphor widely, means disabled. Meanwhile, the students should focus in the study of cultures and conventions during the intermediate stage, where comparison of cultural difference of metaphors should be enhanced. In the advanced stage, the knowledge of metaphor is of vital importance, such as the relationship between metaphor and thought, metaphor and culture, and metaphor and knowledge.

Besides, cultural teaching of metaphor should be combined with language teaching. In addition to explanation of cultures involved in the metaphor, the teachers should improve students' listening, speaking, reading and writing with vocabulary, phrases, sentences and passages. For instance, the sentence that "You are the salt of the earth", being from Bible, is to describe a person who is a pillar of a country. As the meaning of the metaphor is explained, the students acquire not only the meaning of the metaphor, but also vocabulary involved. At the same time, the context of the metaphor should be provided to help the students remember it vividly.

Furthermore, as for vocabulary teaching, metaphors encourage the students to understand the meanings of words thoroughly. At beginning, the teacher can help the students enhance the interpretation of the new words by the process of metaphorizatin. Take "succeed" for example, it consists of "suc" and "ceed". In other words, "suc" means under and "ceed" refers to go, while it's original meaning is subsequent or continual. However, the basic meaning was developed to refer "after a person passed away". Then, it stands for "to inherit". Nowadays, "succeed" means "to fulfill" or "to accomplish". After analyzing the development of the word, the teachers make students understand the meaning of the word vividly and remember it easily.

Meanwhile, creative thought should be developed with the cognitive rules of metaphors. In the process of teaching, the duty of the teacher is to encourage the students' imagination and convey their thought with metaphors. At the same time, the students should compile the poems with English or Chinese. After class, the students should do more translation on metaphors from English to Chinese, which not only help the students improve their literary accomplishment, but also make the students obtain creative mind in the process of translating.

In addition, the students should be trained on metaphor competence. On the one hand, the students are supposed to read more poems to develop their literary accomplishment. Because metaphors are the life of poems and both of them have similar characters. It is of very significance for the students to develop their metaphor competence with more poems, which not only enrich the students' expressions in language, but also broaden their mind. On the other hand, the students are required to collect expressions on metaphors and to probe the subtle forms of metaphors. The more poems the students recite, the higher metaphor competence the students will acquire.

Also, it is advisable that autonomic learning should be advocated among the students. In other words, the students can make full use of Internet to grasp the meanings of the metaphors. For example, the students can assess their own compositions online with model essays or the other students' compositions under the standard of the appropriate use of metaphors for the purpose of comparing the different metaphors used by different students. Also, data base is of great significance in building the students' creative metaphor competence. The students can take a metaphor as a core, and search the other metaphors that are related to the core metaphor, which would let the students make clear about the relationship between vocabulary and grammar, the position of a metaphor in a sentence and the reason why different metaphors are employed in different countries.

\section{CONCLUSION}

Therefore, metaphor is a synthesis combined with form, meaning, pragmatic function and personality emotion, instead of a simple form. Metaphor is a figurative phenomenon, an important tool in language communication; what's more, it has a closed relationship with many subjects, such as Literature, Aesthetics, Sociology, Philosophy, Logic and so on, for metaphor can permeate into one's subjective thinking and concept of aesthetic. One's personality, including philosophy, culture, standard of aesthetics and so on, will be reflected through the metaphor one uses. Only when the teaching methods of metaphors are employed properly, can the students' creative thought and critical thinking skills be cultivated in the process of language learning.

\section{REFERENCES}

[1] Dang Jinxue. Selected reading of Translation Theories from China and Western Countries [M]. Xi'an: Shanxi People's Publishing House, 2005

[2] Mona-Baker. Rutledge Encyclopedia of Translation Studies[M] Shanghai: Shanghai Foreign Language Education Press, 2004 
[3] Mary-Snell-Hornby. Translation Studies: An Integrated Approach [M]. Shanghai: Shanghai Foreign Language Education Press, 2001

[4] Ernst-August Gutt. Translation and Relevance: Cognition and Context $[\mathrm{M}]$. Shanghai: Shanghai Foreign Language Education Press, 2004

[5] Xu Zhanghong. Metaphor Understanding: A Pragma-Cognitive Approach [M]. Beijing : Science Press, 2007 